\title{
In vitro Callusing and Regeneration in Trifolium resupinatum-A Fodder Legume
}

\author{
Devendra R. Malaviya*, Ajoy K. Roy, Aparna Tiwari, \\ Pankaj Kaushal and Bijendra Kumar \\ Crop Improvement Division Indian Grassland and Fodder Research Institute Jhansi 284003 India
}

Received March 21, 2006; accepted May 20, 2006

\begin{abstract}
Summary In vitro regeneration protocol was developed in Trifolium resupinatum, an important fodder legume in Northwestern India. Out of 6 explants (leaf, petiole, hypocotyl, cotyledon, collar and root) tried for callus induction in 2 different media, good response was observed from hypocotyl and root explants in 'A' medium. Successful regeneration was obtained from callus induced from hypocotyl, cotyledon and root in 'A' followed with subculture in ' $E$ ' medium. One of the regenerated plantlet was characterized and compared with mother plant for isozyme-banding pattern. Wide variation for isozyme banding pattern for SOD, Peroxidase and GOT enzyme indicates the regenerant to be a somaclonal variant. Thus, in vitro regeneration will help in widening the genetic base of the species.
\end{abstract}

Key words Trifolium resupinatum, Fodder, Regeneration, Tissue culture.

Plant tissue, cell and protoplast cultures are useful tools for crop improvement, especially as supplementary means of inducing variability through tissue culture instability and somaclonal variations (Scowcroft 1984). Trifolium resupinatum (Shaftal or Persian clover) is an important cultivated winter annual fodder legume grown widely in subtropical and sub temperate areas of India. The species has previously been frequently introduced in different parts of Europe and cultivated as fodder crop in northwestern subtropical zones. It is a multicut crop and is favoured by farmers for its high quality, good yield and tolerance to biotic and abiotic stress.

Narrow genetic base in this crop hampers its genetic improvement programme. The conventional breeding efforts have failed to generate variability for making effective selection. In this study, efforts were made to develop and characterize somaclonal variants in this crop by using in vitro tissue culture methods.

Materials and methods

Healthy seeds of $T$. resupinatum ( $\mathrm{SH} 97-49$ ) were surface sterilized using $0.1 \% \mathrm{HgCl}_{2}$ for 2 min followed by 4-5 rinsing with sterile water and germinated on basal MS medium (Murashige and Skoog 1962) containing 3\% sucrose and 0.7\% agar without any growth regulators. Six explants viz., leaf, petiole, hypocotyl, cotyledon, collar and root were taken from $21-23 \mathrm{~d}$ old seedlings. Two combinations of auxin and cytokinin in the medium were studied for callus induction efficiency. The medium 'A' contained L2 basal medium (Phillips and Collins 1984) supplemented with $0.05 \mathrm{mg} / 1 \mathrm{NAA}$ and $0.1 \mathrm{mg} / 1 \mathrm{BAP}$, whereas medium 'A-1' contained L2 basal medium supplemented with $0.1 \mathrm{mg} / \mathrm{l}$ BAP. Initially the explants were kept in dark for callus induction and after $5 \mathrm{~d}$ of inoculation the cultures were provided with a photoperiod of $10 \mathrm{~h}$. After shoot emergence, the light

Abbreviations: SOD: super oxide desmutase, GOT: glutamate oxalo acetate transaminase, PRX: peroxidase, Est: esterase, Acp: acid phosphatase, BAP: 6-benzyl amino purine, NAA: naphthaleneacetic acid, IAA: indole-3-acetic acid.

* Corresponding author, e-mail: drmalaviya47@rediffmail.com 
period was increased to $12 \mathrm{~h}$. The cultures were maintained at $24 \pm 2^{\circ} \mathrm{C}$.

In each set, a total of 30 explants per explant-media-genotype combination ( 5 sets each having 3 culture tubes with 2 explants each) were inoculated. Periodical observations were recorded on nature, colour and growth rate of callus. After 30-35 d, the calli were split and subcultured in 10 tubes containing shoot inducing medium 'E' (L2 basal medium $+0.0008 \mathrm{mg} / 1 \mathrm{NAA}+0.15 \mathrm{mg} / \mathrm{l} \mathrm{BAP}$ ). Shoot multiplication was done by one more round of subculturing in the same culture medium. The shoots were split and subcultured again on root induction medium 'RL1' (RL basal medium supplemented with $0.21 \mathrm{mg} / \mathrm{l} \mathrm{IAA}$ ). The regenerated plantlets in the culture tubes were kept out of the culture room for $2-3 \mathrm{~d}$ at room temperature $\left(30^{\circ} \mathrm{C}\right)$. The plants were taken out of the culture tubes, freed of media and kept for an additional day with the roots submerged in sterilized distilled water containing crushed nodules from T. alexandrinum plants growing in field following Roy et al. $(2004,2005)$ and covered with cellophane paper to maintain high humidity. These plants were protected from direct sunlight for the first $3-5 \mathrm{~d}$ in the field.

One of the regenerant, the mother plant and 5 germplasm lines were studied for isozyme variation involving 5 enzyme systems viz., esterase (Est), super oxide desmutase (SOD), acid phosphatase (Acp), glutamate oxaloacetate transaminase (GOT) and peroxidase (PRX). Horizontal starch gel electrophoresis technique (Smithies 1955) with discontinuous buffer system (Poulik 1957) was used. The crude extract of young, green leaves was prepared by homogenizing $1 \mathrm{~g}$ of sample with $0.3 \mathrm{ml}$ of chilled Tris buffer $(9.206 \mathrm{~g}$ Tris and $1.051 \mathrm{~g}$ citric acid/1000 $\mathrm{ml}$ double distilled water, $\mathrm{pH}$ 8.65). The crude extract was filtered through muslin cloth and stored at $-20^{\circ} \mathrm{C}$ in different vials and thawed just before use. Electrophoresis was carried out using $14 \%$ hydrolysed potato starch gel in 'Genei' horizontal migration chamber at constant current of $24 \mathrm{~mA}$ for first $30 \mathrm{~min}$ followed with $34 \mathrm{~mA}$. The gels were stained following the method of Veech (1969) for peroxidase and Wendel and Weeden (1989) for other enzymes.

The data obtained for callus induction in different media-explant combinations were grouped and mean \pm standard deviation was calculated. The isozyme pattern among the regenerate and the mother plant was compared using Dice's similarity matrix and dendrogram was generated following UPGMA method.

\section{Results}

In vitro response of various explant-media combinations were studied using the parameters such as callus induction frequency, nature and growth rate of callus, subculturing response towards organogenesis and embryogenesis.

Seeds of T. resupinatum (genotype SH 97-49) germinated within 5-6 d and developed into 3.5 to $4.0 \mathrm{~cm}$ long seedlings in $21-23 \mathrm{~d}$. At this stage, explants like hypocotyl, petiole, cotyledon, leaf, collar and root were excised and cultured on 2 media for callus induction (Table 1).

Leaf: Poor response of explants was observed in 'A-1' medium with only $16.7 \%$ explants resulting in callus induction. In 'A' medium moderate response (30\%) of callus induction was found. The calli in both the media were friable, yellow in colour and slow growing.

Petiole: In 'A-1' medium, $43 \%$ of explants developed into callus. The swelling of explants was observed within 4-6 d and friable yellow callus was formed. The rate of growth was slow to medium. A better response (67\%) of callus induction was observed in 'A' medium. The rate of growth of friable, yellow to hyaline calli was slow to medium and they reached a diameter of 4-5 $\mathrm{mm}$ in $35 \mathrm{~d}$.

Cotyledon: In 'A-1' medium, $50 \%$ of the explants showed callusing. The callus of $4.5-5 \mathrm{~mm}$ diameter was formed in 25-27 d of culture. The callus formed was compact and yellow green. In the medium ' $A$ ' $68.7 \%$ explants formed callus. Callusing initiated in $12-14 \mathrm{~d}$ and reached the size of $6.5-7 \mathrm{~mm}$ in diameter in the next $10-11 \mathrm{~d}$. The calli were compact and nodular and yellow to light green. The rate of growth was medium to high in different sets. 
Table 1. Callusing response of T. resupinatum explants in different media

\begin{tabular}{|c|c|c|c|c|c|c|}
\hline \multirow{2}{*}{$\begin{array}{l}\text { Explant } \\
\text { source }\end{array}$} & \multirow{2}{*}{ Media } & \multirow{2}{*}{$\begin{array}{c}\text { No. of } \\
\text { explants }\end{array}$} & \multirow{2}{*}{$\begin{array}{l}\% \text { Callus } \\
\text { induction }\end{array}$} & \multicolumn{3}{|c|}{ Callus characteristics } \\
\hline & & & & Nature & Colour & Growth rate \\
\hline \multirow[t]{2}{*}{ Leaf } & A-1 & 30 & $16.7 \pm 20.41$ & Friable & Yellow & Slow \\
\hline & $\mathrm{A}$ & 30 & $30.0 \pm 18.26$ & Friable, compact & Yellow, pale green & Slow \\
\hline \multirow[t]{2}{*}{ Petiole } & A-1 & 30 & $43.3 \pm 38.37$ & Friable & Yellow & Slow, medium \\
\hline & A & 30 & $66.7 \pm 20.48$ & Friable & Yellow, hyaline & Slow, medium \\
\hline \multirow[t]{2}{*}{ Cotyledon } & A-1 & 30 & $50.0 \pm 11.79$ & Compact & Yellow, Green & Medium \\
\hline & $\mathrm{A}$ & 28 & $68.7 \pm 12.38$ & Compact, Nodular & Pale Green, Yellow & Medium, High \\
\hline \multirow[t]{2}{*}{ Hypocotyl } & A-1 & 30 & $50.0 \pm 26.35$ & Friable & Yellow & Slow \\
\hline & A & 28 & $92.7 \pm 10.11$ & Friable & Yellow, Green & Medium, High \\
\hline \multirow[t]{2}{*}{ Collar } & A-1 & 25 & $36.0 \pm 21.91$ & Friable, compact & Hyaline & Slow \\
\hline & $\mathrm{A}$ & 25 & $20.0 \pm 24.49$ & Compact & Yellow & Medium, slow \\
\hline \multirow[t]{2}{*}{ Root } & A1 & 27 & 0 & - & - & - \\
\hline & $\mathrm{A}$ & 26 & 100 & Friable & Yellow, Pale Green & High \\
\hline
\end{tabular}

'A' medium=L2 basal +0.05 mg/1 NAA +0.1 mg/1 BAP, 'A-1' medium=L2 basal +0.1 mg/1 BAP.
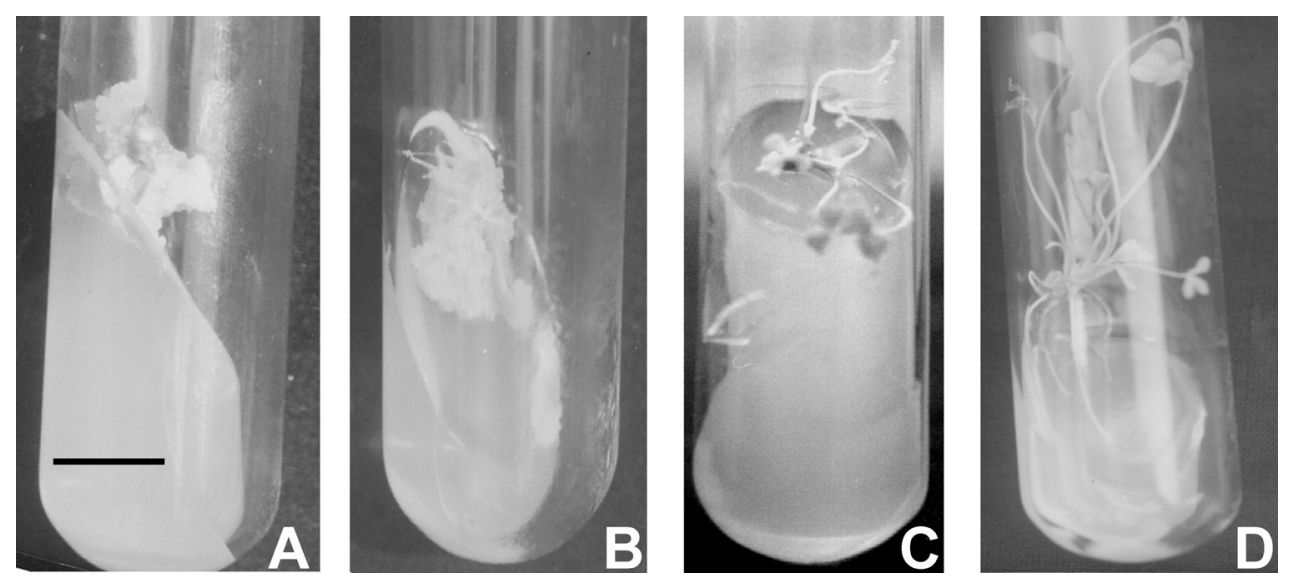

Fig. 1. In vitro callusing and regeneration in T. resupinatum. A. Callusing, B. Organogenesis in calli, C and D. Regenerated plantlet $(\mathrm{Bar}=1 \mathrm{~cm})$.

Hypocotyl: In 'A-1' medium, the explants showed a good response $(50 \%)$ of callus induction. Swelling was observed in 9-11 d and pale yellow, friable callus was initiated in $17-19 \mathrm{~d}$. The callus was slow growing and attained the size of $4-4.5 \mathrm{~mm}$ in diameter in 28-30 d. In the medium ' $A$ ' almost all the explants responded positively for callus induction and proliferation. Swelling in the explants was induced in 9-11 d and friable, green callus was induced in $13-14 \mathrm{~d}$ which after $35 \mathrm{~d}$ reached the size of $8-8.5 \mathrm{~mm}$ diameter, the callus growth was nodular with tuber like protu-

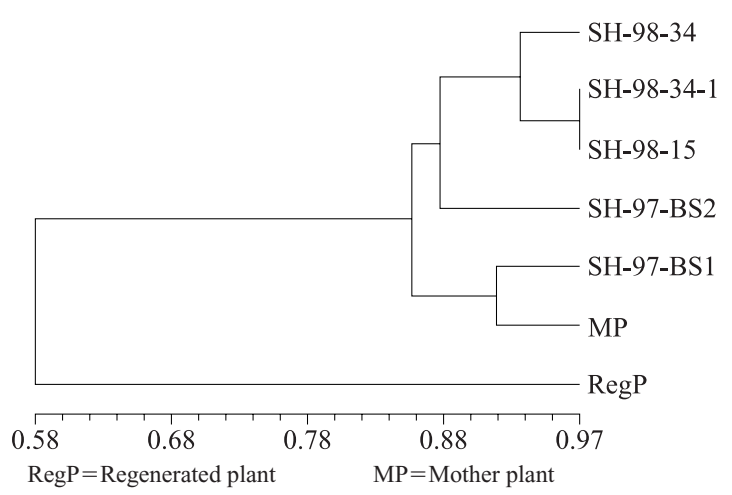

Fig. 2. Similarity among mother plant, regenerant and germplasm of $T$. resupinatum. 
Table 2. Response to subculturing of different explant-media combination callus

\begin{tabular}{|c|c|c|c|c|c|c|c|c|c|c|}
\hline \multirow{2}{*}{$\begin{array}{l}\text { Explant } \\
\text { source }\end{array}$} & \multirow{2}{*}{$\begin{array}{c}\text { Callusing } \\
\text { media }\end{array}$} & \multicolumn{4}{|c|}{$\begin{array}{l}\text { Response of callus to } \\
\text { shooting media on } \\
\text { subculture }(\%)\end{array}$} & \multicolumn{3}{|c|}{$\begin{array}{l}\text { Response of shoots to } \\
\text { rooting media (RL1) } \\
\text { on subculture }(\%)\end{array}$} & \multirow{2}{*}{$\begin{array}{l}\text { Complete } \\
\text { plantlets } \\
(\%)\end{array}$} & \multirow{2}{*}{$\begin{array}{l}\text { Field } \\
\text { transfer } \\
(\%)\end{array}$} \\
\hline & & NR & $\mathrm{CP}$ & Shooting & Rooting & NR & Shooting & Rooting & & \\
\hline Hypocotyl & A & 50.0 & 30.0 & 20.0 & - & 37.5 & 62.5 & 37.5 & 37.5 & 25.0 \\
\hline Cotyledon & A & 50.0 & 20.0 & 20.0 & 10.0 & 37.5 & 37.5 & 25.0 & 25.0 & - \\
\hline Root & A & 40.0 & 40.0 & 20.0 & - & 40.0 & 16.7 & 33.3 & 33.3 & 60.0 \\
\hline
\end{tabular}

NR: No response, CP: Callus proliferation, E medium: L2 basal +0.0008 mg/l NAA +0.15 mg/1 BAP, RL1 medium: RL basal+0.21 mg/l IAA.

Table 3. Isozyme banding pattern in regenerated and mother plant along with other genotypes of $T$. resupinatum

\begin{tabular}{|c|c|c|c|c|c|c|}
\hline \multirow{2}{*}{ Genotype } & \multirow{2}{*}{ Esterase } & \multirow{2}{*}{ SOD } & \multicolumn{2}{|c|}{ Peroxidase } & \multirow{2}{*}{$\mathrm{ACP}$} & \multirow{2}{*}{ GOT } \\
\hline & & & Anodal & Cathodal & & \\
\hline SH-98-34 & $3,5,6$ & $1,2,3$ & 1,2 & 3,4 & 1,2 & $1,2,3,4,5$ \\
\hline SH-98-34-1 & $3,5,6$ & $1,2,3$ & 1,2 & $2,3,4,5$ & 1,2 & $1,2,3,4,5$ \\
\hline SH-98-15 & $3,5,6$ & $1,2,3$ & 1,2 & $2,3,4,5$ & $1,2,3$ & $1,2,3,4,5$ \\
\hline SH-97-BS1 & $4,5,6$ & $1,2,3$ & 1,2 & $2,3,5$ & $1,2,3$ & $1,2,3,4,5$ \\
\hline SH-97-BS2 & $1,2,5,6$ & $1,2,3$ & 1,2 & 3,4 & 1,2 & $1,2,3,4,5$ \\
\hline SH-98-49 (Mother plant) & 4,6 & $1,2,3$ & 1,2 & 3,5 & 1,2 & $1,2,3,4,5$ \\
\hline SH-98-49R (Regenerated plant) & 4,6 & 1,3 & 1,2 & $1,2,4$ & 1,2 & 3,4 \\
\hline
\end{tabular}

berances (Fig. 1A, B).

Collar: In 'A-1' medium, moderate response (36\%) of callus induction was noticed. The callus was friable/compact, slow growing and hyaline. In 'A' medium, the response of explants for callus induction was poor $(20 \%)$. The callus was compact and slow to medium growth rate was observed in different sets. However, the colour was yellow and no green pigmentation was observed.

Root: In 'A-1" medium, the root explants failed to show any positive response for callusing. But in 'A' medium almost all the explants formed friable, yellow calli. Though the callus proliferated vigorously, it failed to develop pigmentation and remained hyaline to pale yellow in colour.

Organogenesis: The calli obtained from each explant media combination were split and cultured in 10 tubes each in shoot inducing medium ' $E$ ' (L2 basal medium $+0.0008 \mathrm{mg} / 1$ $\mathrm{NAA}+0.15 \mathrm{mg} / \mathrm{l} \mathrm{BAP})$. No positive response of subculturing was observed in the calli developed from leaf, petiole and collar. Only callus proliferation was observed.

Calli developed from cotyledon in 'A' medium showed shoot induction in 2 tubes after 15-17 d of culture in ' $\mathrm{E}$ ' medium. Root induction was also observed simultaneously in one tube but roots turned brown. Further subculture in root inducing medium 'RL' produced roots and complete plantlets were obtained in 2 out of 8 cases. However, none of the plants could survive during the process of transfer (Table 2).

Hypocotyl induced calli in ' $A$ ' medium showed positive response towards organogenesis and shoots emerged after $12-15 \mathrm{~d}$ of subculture. The shoots were multiplied by one more round of subculture in ' $\mathrm{E}$ ' medium. The shoots were split and subcultured in root induction medium 'RL' (RL basic $+0.21 \mathrm{mg} / 1$ IAA). Successful rooting was observed in $37.5 \%$ cases (Fig. 1C, D). In-vitro flow- 
ering was also observed in 2 plantlets. These plantlets were successfully transferred to the field with $25 \%$ success rate.

The calli formed in 'A' medium from root showed positive response towards shoot induction. These shoots were also multiplied in ' $E$ ' medium and subcultured in 'RL' medium for root induction. Success was obtained in development of plantlets (33.3\%) and transfer to field (60\%).

\section{Characterization of regenerant by isozyme banding pattern}

In-vitro regenerant and the mother plant of $T$. resupinatum were compared by studying the isozyme profiles of five enzymes. Five other accessions of $T$. resupinatum were also included to get the comparative profile of the variation found in the species (Fig. 2, Table 3).

A total of 6 bands were observed for esterase isozyme at $0.58,0.61,0.63,0.72,0.77$ and $0.90 \mathrm{rm}$. The mother plant and regenerated plant showed a similar banding pattern of only 2 bands (bands 4 and 6). For SOD, three bands at $0.52,0.73$ and $0.87 \mathrm{rm}$ were observed. Band no. 2 was absent in regenerant as compared to its mother plant. Intensity of Band 1 was very dark in the regenerated plant as compared to its mother plant. For Acp, three bands at $0.45,0.58$ and $0.73 \mathrm{rm}$ values were recorded. There was no difference for banding pattern between mother plant and regenerant.

For GOT, considerable variation for isozyme pattern was observed between regenerant and its mother plant. Total 5 bands at $0.31,0.33,0.39,0.44$ and $0.47 \mathrm{rm}$ were observed in mother plant in contrast to only 2 bands ( 3 and 4 ) present in the regenerant. There was no variation in different accessions of the species and all the accessions shared 5 bands. Variation was also observed for peroxidase cathodal banding pattern. Bands 1, 2, 4 were present in regenerant whereas bands 3, 5 were found in mother plant.

Similarity index: Similarity matrix analysis using Dice's co-efficient showed that the regenerant was only $58 \%$ similar to the mother plant. The mother plant and other accessions of the T. resupinatum used in this study showed 86 to $97 \%$ similarity among themselves, whereas the regenerant showed a totally different isozyme pattern, thereby confirming the development of new somaclonal variants.

\section{Discussion}

The objective of the study was to develop an effective in vitro regeneration protocol of the species and to identify the somaclonal variations. Two media formulations were used to study the in vitro callus induction response in this species. The 2 media named as ' $\mathrm{A}$ ' and 'A-1' differed in the growth hormone composition. A-1 medium comprised of L2 basal supplemented with $0.1 \mathrm{mg} / 1$ BAP, whereas 'A' medium was provided with both auxin in the form of NAA $(0.05 \mathrm{mg} / \mathrm{l})$ and cytokinin in the form of BAP $(0.1 \mathrm{mg} / \mathrm{l})$. Callus inducing response was better in medium ' $\mathrm{A}$ ' for all the explant source except collar. It indicates that media with both auxin and cytokinin content are better for callus induction. Regeneration potential was also good in the calli, which were originally developed on 'A' medium. The calli obtained from 'A-1' medium from any explant source did not show organogenesis and only callus proliferation was noticed and the calli turned brown after 15-20 d. Good organogenetic potential was noticed in the calli developed from cotyledon, hypocotyl and root in ' $A$ ' medium where shoot formation was noticed. These shoots also produced roots when transferred to 'RL1' medium.

The study also points to the fact that although callus formation was observed in A-1 medium, it did not respond to organogenesis, which indicate the role of auxin in differentiation process. Previous reports have indicated that ratio of auxin and cytokinin plays a significant role in organogenesis. In tobacco, high ratio of auxin to cytokinin favoured root formation, the reverse favoured shoot formation and an intermediate ratio promoted callus proliferation (Skoog and Miller 1957).

The callus induction frequency, nature of calli and their growth rate were found to be depen- 
dent on different combinations. The differential response of explants to varying hormonal concentration can be attributed to the nature of explant tissue, its genetic potential for regeneration and hence, its nutritional requirement. It was observed that only friable, green calli were responsive to organogenesis in shoot inducing media (medium 'E'). Successful shoot induction was observed only in calli derived from 'A' medium of hypocotyl, cotyledon and root explants.

In the present programme, regenerant was compared with mother plant using isozyme banding pattern. Variation was recorded between mother plant and regenerant for SOD, peroxidase and GOT while no difference was observed for esterase and acid phosphatase.

Isozyme profile of GOT, a very important enzyme for transfer of amine groups, has shown wide variation. The mother plant showed the presence of 5 bands whereas in the regenerant only band numbers 3 and 4 were recorded. It indicates that the first 2 bands with high molecular weight and low mobility and the last band with high mobility and low molecular weight are absent in regenerant. Isozyme patterns of SOD in regenerant also indicate absence of band number 2 out of total 3 bands present in the mother plant.

Peroxidase isozymes are members of a large multigenic family and are involved in a broad range of physiological processes all along the plant life cycle. The main processes include auxin metabolism, lignin and suberin formation, cross-linking of cell wall components, defence against biotic and abiotic stress etc. (Passardi et al. 2005). Wide variation for cathodal bands of this enzyme was observed in mother and regenerant. In fact, a slow migrating band was observed in the regenerant, which was not present in mother plant as well as other accessions of this species. Novel acid phosphatase bands during cytodifferentiation in callus cultures of Vigna were also reported (De and Roy 1984). In this study also novel bands of peroxidase were found.

Isozymes are multiple molecular forms of an enzyme with similar or identical substrate specificities occurring within the same organism (Markert and Moller 1959). Isozyme patterns have been used to detect changes during regeneration as they play a vital role in development and differentiation (Orton 1983, Evans et al. 1984, Chawla 1988). Isozyme study has been suggested as a valuable tool in identifying genetic and epigenetic changes (Michel 1975). Alterations in phosphoglucomutase and shikimate dehydrogenase phenotype were observed in regenerated celery plants, which were also correlated with karyotypic changes (Orton 1983).

Isozyme analysis has previously been reported to explain the genetic basis of certain somaclonal variations. Changes in isozyme pattern in somaclonal variants have been reported in celery (Orton 1983) and wheat (Davies et al. 1986). Modification of wheat B-amylase phenotype with additional activity bands, where the meiotic and mitotic chromosomal configurations were normal, has been reported by Ryan and Scowcroft (1987).

Previous reports indicate that the somaclonal variation is derived either from the release of pre-existing genetic diversity in the explants or else from the variability originating during cell dedifferentiation or callus maintenance in vitro. It has been reported to be dependent on the plant species, the genotypes, the type of explant, culture, media formulations etc. Type of culture and media combination has been found to influence the generation of somaclonal variation. Leaf callus culture was found to be more efficient in comparison to cytokinin dependent cell suspension and liquid culture of meristematic clumps in Cucumis (Filipecki et al. 2005, Ladyzynski et al. 2002).

Plant tissue culture per se has long been considered as a rich and novel source of genetic variation. Development of somaclonal variants through callus phase is a cheaper source as compared to other biotechnological tools such as somatic hybridization, genetic transformation, DNA recombination etc. This method can be exploited in species having limited genetic diversity provided a suitable regeneration protocol is developed. The present study resulted in development of regeneration protocol in T. resupinatum genotype and characterization of new somaclonal variants. 


\section{Acknowledgements}

Authors wish to thank Director, IGFRI, Jhansi and Head, Crop Improvement Division, IGFRI for facilities and encouragement. Financial support for ICAR in the form of AP CESS fund project and fellowship to 2 authors (BK and AT) are also acknowledged.

\section{References}

Chawla, H. S. 1988. Isozyme modifications during morphogenesis of callus from barley and wheat. Plant Cell Tissue Organ Culture. 12: 299-304.

Davies, P. A., Pallotta, M. A., Ryan, S. A., Scowcroft, W. R. and Larkin, P. J. 1986. Somaclonal variation in wheat: genetic and cytogenetic characterisation of alcohol dehydrogenase mutants. Theor. Appl. Genet 72: 644-653.

De, K. K. and Roy, S. 1984. Role of an acid phosphatase isoenzyme in callus tissue during cyto-differentiation. Theor. Appl. Genet 68: 285-287.

Evans, D. A., Sharp, W. R. and Medina-Filho, H. P. 1984. Somaclonal and gametoclonal variation. Amer. J. Bot. 71: 759-774.

Filipecki, M., Wisniewska, A., Yin, Z. and Malepszy S. 2005. The heritable changes in metabolic profiles of plants regenerated in different types of in vitro culture. Plant Cell, Tissue Organ Cult. 82: 349-356.

Ladyzynski, M., Burza, W. and Malepszy, S. 2002. Relationship between somaclonal variation and type of culture in cucumber. Euphytica 125: 349-356.

Markert, C. L. and Moller, F. 1959. Multiple forms of enzymes, tissue, ontogenetic and species specific patterns. Proc. Natl. Acad. Sci. USA 45: 753-763.

Michel, J. 1975. Isozymes and strategy for their utilization in plant genetics genetic and Epigenetic control. L. In: Lucein (ed.), Genetic Manipulation with Plant Material. Plenum Press. New York and London. pp. 368-378.

Murashige, T. and Skoog, F. 1962. A revised medium for rapid growth and bioassays with tobacco tissue cultures. Physiol. Plant. 15: 473-497.

Orton, V. J. 1983. Spontaneous electrophoretic and chromosomal variability in callus cultures and regenerated plants of celery. Theor. Appl. Genet. 67: 17-24.

Passardi, F., Cosio, C., Penel, C. and Dunand, C. 2005. Peroxidases have more functions than a swiss army knife. Plant Cell Rep 24: 255-265.

Phillips, G. C. and Collins, G. B., 1984. Red clover and other forage legumes. In: Sharp, W. R., Evans, D. A., Ammirato, P. V. and Yamada, Y. (Eds.), Hand Book of Plant Cell Culture. Macmilllan Publ Co. New York Vol. 2. pp. 169-210.

Poulik, M. D. 1957. Starch gel electrophoresis in a discontinuous system of buffers. Nature 180: 1477-1479.

Roy, A. K., Malaviya, D. R., Kaushal, P., Kumar, B. and Tiwari, A. 2004. Interspecific hybridization of T. alexandrinum with T. constantinopolitanum using embryo rescue. Plant Cell Rep. 22: 605-610.

-, Tiwari, A., Malaviya, D. R., Kaushal, P. and Kumar, B. 2005. Regeneration efficiency in Trifolium apertum as influenced by explant media interaction. Cytologia 70: 153-159.

Ryan, S. A. and Scowcroft, W. R. 1987. A somaclonal variant of wheat with additional B-amylase isozymes. Theor. Appl. Genet. 73: 459-464.

Scowcroft, W. R. 1984. IBPGR Report, Genetic variability in tissue culture. Impact on germplasm, conservation and utilization. A technical report commissioned by in vitro storage committee. pp. 1-41.

Skoog, F. and Miller, C. D. 1957. Chemical regulation of growth and bud formation in plant tissues culture in vitro. Symp. Soc. Exp. Biol. 11: 118-131.

Smithies, O. 1955. Zone electrophoresis in starch gel: group variation in the serum proteins of normal human adults. Biochem. J. 61: 629-641.

Veech, J. A. 1969. Localization of peroxidase in infected tobaccos susceptible and resistant to black shank. Phytopathology 59: 556-571.

Wendel, J. F. and Weeden, N. F. 1989. Visualization and interpretation of plant iosozymes. In: D. S. Soltis and Soltis, P. S. (eds), Isozymes in Plant Biology, Chapman and Hall. London 